\title{
AGING AFFECTS RESPONSE TO CYCLIC TENSILE STRETCH: PARADIGM FOR INTERVERTEBRAL DISC DEGENERATION
}

\author{
Hongsik Cho ${ }^{1,2,3}$, Aman Seth ${ }^{1}$, Jenna Warmbold ${ }^{1}$, James T. Robertson ${ }^{1}$ and Karen A. Hasty ${ }^{1,2,3, *}$ \\ ${ }^{1}$ University of Tennessee Health Science Center, Memphis, TN, USA \\ ${ }^{2}$ Campbell Clinic, Memphis, TN, USA \\ ${ }^{3}$ Veterans Affairs Medical Center, Memphis, TN, USA
}

\begin{abstract}
Much evidence supports a fundamental role for mechanical forces in modulating differentiation, homeostasis, and remodelling of musculoskeletal cells. Little is known, however, regarding mechanobiology and gene expression of intervertebral disc (IVD) cells from older individuals. To characterise the effect of mechanical stimulation on cells from older discs, an in vitro study of IVD cells harvested from different aged pigs was conducted to measure extracellular matrix (ECM) gene expression in response to cyclic tensile stress (CTS). Gene expression of annulus fibrosus (AF) cells from IVDs of mature and older pigs was quantified for the predominant ECM genes; type I collagen, type II collagen and aggrecan, and matrix metalloproteinase 1 (MMP-1), a collagenase that degrades fibrillar collagens.

AF cells cultured on flexible-bottom plates were stretched $10 \%$ at $0.5 \mathrm{~Hz}$ frequency. After $24 \mathrm{~h}$, gene expression was assayed using reverse transcriptase polymerase chain reaction (RT-PCR). Basal mRNA levels without stretching for type II collagen and aggrecan were lower in older annular cells whereas MMP-1 levels were higher compared to mature cells. Following CTS, an adaptive response was elicited in annular cells from both age groups. ECM protein genes were upregulated, whereas MMP-1 was downregulated. The magnitude of response was significantly greater in older cells as compared to mature cells. These data suggest that the cells from the AF of older animals manifest lower basal levels of mRNA for type II collagen and aggrecan and higher levels of MMP-1 possibly due to decreased tensile stress experienced in vivo and is not the result of reduced capacity for response.
\end{abstract}

Keywords: Intervertebral disc, annulus fibrosus, extracellular matrix, collagen, matrix metalloproteinase, pig.

\footnotetext{
*Address for correspondence:

Karen A. Hasty

Research Service 151, VA Medical Center

Memphis, TN 38104

Telephone Number: 001-901-523-8990 ext. 7632 (office),

FAX Number: 001-901-577-7273

E-mail: khasty@uthsc.edu
}

Although low back pain is one of most common causes of morbidity in developed countries with 60-80\% of people affected at some point in their lives (Kelsy et al., 1992; Sive et al., 2002), its aetiology remains unclear. Genetic, environmental, and psychosocial factors have been suggested to play a role in disc degeneration, which is associated with low back pain in a large proportion of patients (Barrick et al., 2000; Lam et al., 2000; Luoma et al., 2000). Mechanical stress from weight bearing, bending, twisting and lifting is thought to be an important environmental contributor to disc degeneration, although the underlying molecular mechanisms are not understood (Gillett et al., 1988; Robertson, 1993; Hoogendoorn et al., 2000). It is very difficult to distinguish between the degenerative effects of mechanical stress and the molecular response to aging mainly because these effects are inter-related. Defining the pathophysiological process of disc degeneration requires a better understanding of the relationship of disc maturation, the mechanical forces exerted on the IVD and the responsive changes in gene metabolism resulting from these parameters.

IVDs consist of a hydrated proteoglycan rich gel, the nucleus pulposus, which is surrounded by a tough layer of collagen fibrils, the annulus fibrosus (AF). The nucleus is a viscous fluid that can only sustain hydrostatic stress in the form of compression, which acts equally in all directions (An et al., 2004; Ekstrom et al., 2004). As the watery nucleus resists compression, stress is distributed circumferentially (hoop stress) because of the pressure pushing it transversely (Naylor et al., 1954). This stress results in strain (deformation per unit length) on the annular collagen fibres, as it dissipates laterally to the fibres of the AF. Because AF cells are localised between and attached to consecutive annular lamellae of collagen fibres, this strain induces deformation of the cells and the matrix (Rajpurohit et al., 2002). Occupations that produce high or repetitive levels of hydrostatic pressure and tensile stresses in the IVDs are associated with disc degeneration, and these forces are thought to play a direct role in the process through their action on ECM molecules and an indirect role through their effects on cell metabolism (Smith and Hochmuth, 1982; Klein-Nuland et al., 1986; Banes et al., 1990; Ganey et al., 2003).

Various methods have been used to investigate the effects of mechanical stress at the cellular level (Matsumoto et al., 1999), including cyclically-applied tensile stress using a flexible substrate to which cells are attached. In studies involving vascular endothelial and smooth muscle cells, this method of cyclic tensile stress 
(CTS) modulates gene expression and matrix protein synthesis and degradation (Baer et al., 2001). Other approaches developed to deform cells in vitro include cell membrane deformation applied by micropipettes manipulated under microscopic control (Smith et al., 1982), hydrostatic pressure applied in pressure chambers where cells are grown (Klein-Nuland et al., 1986), and shear stress induced by fluids passing over a fixed substrate covered with cells (Banes et al., 1990).

Based on previous studies that showed that age and mechanical stress are factors in ECM metabolism, our study examined three parameters. First, experiments were designed to demonstrate if annular cells from the IVDs of older animals manifest differences in basal ECM metabolism compared to those from mature animals, as measured by gene expression and incorporation of radioisotopes in vitro. Second, we determined if the cellular response to mechanical stress at the molecular level varied according to the age of the animal. Finally, we tested the hypothesis that mechanical stress might abrogate degenerative changes observed in older animals such as decreased proteoglycan synthesis or increased matrix metalloproteinase-1 (MMP-1).

To investigate these aims, in the current study, AF cells from the inner layer of the IVDs of domestic pigs of different ages were cultured on flexible-bottomed culture plates and CTS was applied. The effect of CTS was determined by quantifying changes in gene expression using real-time reverse transcription polymerase chain reaction (RT-PCR) analysis and comparing stretched cells to unstretched controls from the same animal.

\section{Materials and Methods}

\section{Source of tissues}

Normal IVDs used in this investigation were obtained from the lumbar spines of 26 female domestic pigs of varying ages (mature, 6-9 months; and older 2.75-3 years). The spine was sectioned between each of the lumbar discs from 10th thoracic vertebrae (T10) to 5th lumbar vertebrae (L5). The muscles and tendons were removed, and the column was sectioned transversally in the middle of each disc. The AF tissue was isolated from both halves of the disc. The outer edge containing muscle and connection ligaments was removed and the inner edge (transitional) zone touching the NP was also discarded. All the discs appeared healthy without overt signs of degeneration. All pig tissues were taken from the spines of healthy pigs freshly sacrificed for other experiments according to approved protocols and experimental procedures at the University of Tennessee Health Science Center.

\section{Cell isolation and culture}

Primary cells from the inner annular tissues were isolated by $1-2 \mathrm{~h}$ digestion at $37^{\circ} \mathrm{C}$ in $0.05 \%$ Pronase (Boehringer Mannheim, Mannheim, Germany), followed by overnight digestion at $37{ }^{\circ} \mathrm{C}$ in $0.2 \%$ collagenase (Worthington Biochemicals, Lakewood, NJ, USA) using modified F-12K medium (Invitrogen, Carlsbad, CA, USA) with $5 \%$ foetal calf serum (FCS, Atlanta Biologicals, GA,
USA), $4 \mathrm{mM} \mathrm{CaCl}$, and $40 \mathrm{mM}$ HEPES buffer (SigmaAldrich, St. Louis, MO, USA). The cells were washed in $\mathrm{F}-12 \mathrm{~K}$ medium and plated at $1 \times 10^{5}$ cells $/ \mathrm{cm}^{2}$ onto BioFlex plates (Flexcell Intl., Hillsborough, NC, USA) with silicone membrane bottoms coated with gelatin. Cells were cultured at $37{ }^{\circ} \mathrm{C}$ in humidified atmosphere of $5 \% \mathrm{CO}_{2}$ in air, and the medium supplemented with $10 \%$ foetal calf serum, streptomycin $(50 \mu \mathrm{g} / \mathrm{mL})$, penicillin $\mathrm{G}$ $(50 \mathrm{IU} / \mathrm{mL}), \mathrm{L}-$ glutamine $(2 \mathrm{mM})$ and ascorbic acid $(50 \mu \mathrm{g} /$ $\mathrm{mL}$ ). The medium was changed every other day until the cells were confluent. For mature cell cultures, confluence occurred in 3-4 d (average doubling time is $1.7 \mathrm{~d}$ ); with older cells, this interval was 5-8 d (average doubling time is $3.9 \mathrm{~d}$ ). Doubling time was calculated using the method developed by V. Roth (http://www.doubling-time.com). Medium was replaced with serum free medium when the cells were confluent and before stimulation by CTS.

\section{Cyclic tensile stress (CTS)}

CTS was applied using a Flexcell stress unit (Flexcell ${ }^{\mathrm{TM}}$ FX4000) consisting of a computer-controlled vacuum unit and base plate to hold the six-well flexible-bottom culture plates. Vacuum was applied to the culture plates through a base plate, which resulted in radial and circumferential strains applied to each flexible membrane. The frequency and duration of elongation were controlled by the computer, with a linear relationship between the vacuum level and the percentage of cell elongation (Matsumoto et al., 1999; Rannou et al., 2000). Previous studies in our lab have shown that a stretch magnitude of $8-12 \%$ does not significantly influence the environment with respect to temperature or cell detachment of monolayer cultures of annular cells on Flexcell plates (Rannou et al., 2000).

AF cells were cultured in similar conditions in six-well flexible-bottomed culture plates coated with gelatin. The cells were treated with serum-free $\mathrm{F}-12 \mathrm{~K}$ culture medium at least $1 \mathrm{~h}$ before application of CTS. Stretching of the cells was performed with application of sinusoidal strain at $0.5 \mathrm{~Hz}$ frequency with a maximum of $10 \%$. A stretch duration of $24 \mathrm{~h}$ at $37^{\circ} \mathrm{C}$ was programmed for $10 \%$ strain with experimental duplicates of each specimen, with unstretched controls for each parametric combination of time and strain. After stretching, cells were removed by trypsinisation and counted using trypan blue staining. A portion of the cells was extracted for RNA with Trizol for RT-PCR analyses.

\section{Western blotting of MMP-1 in culture supernatants}

Cells were cultured for $24 \mathrm{~h}$ in serum-free medium, the supernatants were collected and centrifuged to remove any cell debris, and the proteins were precipitated by the addition of four volumes of cold acetone, and then centrifuged at $13,000 \times \mathrm{g}$ for $10 \mathrm{~min}$. The precipitate was mixed with Laemmli sample buffer and separated by SDS/PAGE, and the proteins were electrophoretically transferred to PVDF membranes (Amersham Bioscience/ GE Healthcare, Amersham, UK). Blots were blocked

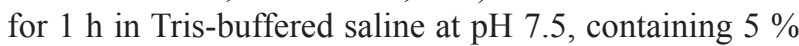
$(\mathrm{w} / \mathrm{v})$ fat-free powdered milk and incubated overnight at $4{ }^{\circ} \mathrm{C}$ with polyclonal antibody to porcine MMP-1 (1:1000, Biodesign Intl., Saco, ME, USA). Membranes 
Table 1. Primer and probe sequences for real time PCR analyses.

These are specific to the pig genome and were custom designed using Primer Express software from Applied Biosystems, CA (Note: Col-I; type I collagen, Col-II; type II collagen, PTGL; Aggrecan, MMP-1; matrix metalloproteinase 1).

\begin{tabular}{|c|c|c|c|c|c|}
\hline Gene & Basepairs & Forward Primer & Reverse Primer & Probe & Genebank \\
\hline Col..$\left.\right|^{* \star}$ & 120 & 5'-AGAAGAAGACATCCCACCAGTCA-3' & 5'-AGATCACGTCATCGCACAACA-3' & 5'-AACGGCCTCAGGTACCATGACCGA-3' & AF20173 \\
\hline Col-.l* & 51 & 5'-CAGGTGAAGGTGGGAAACCA-3' & 5'-ACCCACGAGGCCAGGA-3' & 5'-ATCAGGGCGTTCCTGGTGAAGCTG-3' & AF20174 \\
\hline PTGL* & 66 & 5'- CCCAACCAGCCTGACAACTT-3' & 5'-CCTTCTCGTGCCAGATCATCA-3' & 5'-ACGCAGTCCTCTCCAGTGGCGAA-3' & $X 60107$ \\
\hline MMP.|** & 121 & 5'-AAGCAGACATAATGATATCCTTTGTCA-3' & 5'-TGAGCATCCCCTCCAATACCT-3' & 5'-CCTTGCTCATGCTTTTCAGCCAGGC-3' & $\times 54724$ \\
\hline GAP.2* & 74 & 5'-TCGGAGTGAACGGATTTGG-3' & 5'-GCCAGAGTTAAAAGCAGCCCT-3' & 5'-CGCATCGGGCGCCTGGTC-3' & AF017079 \\
\hline Beta Actin ${ }^{\star \star}$ & 85 & 5'-TCCAGAGGCGCTCTTCCA-3' & 5'-CGCACTTCATGATCGAGTTGA-3' & 5'-CCTTCCTGGGCATGGAGTCCTGC-3' & SSU07786 \\
\hline
\end{tabular}

were washed in Tris-buffered saline and incubated with anti-rabbit antibody coupled to alkaline phosphatase (1:10,000, Amersham). Excess antibody was removed by washing, and immunoreactive bands were visualised by incubation with ECF substrate (Amersham), according to the manufacturer's instructions. The fluorescence was detected on a STORM 860 reader (Molecular Dynamics, Sunnyvale, CA, USA), and the immunoreactive band was quantitated using ImageQuant (GE Healthcare) Software.

\section{Real-time RT-PCR}

Total RNA from the cell cultures was prepared using a TRIZOL reagent (Life Technologies). Both total RNA concentration and its purity were determined at $260 \mathrm{~nm}$ and $280 \mathrm{~nm}$ UV wavelengths using a Nanodrop ${ }^{\mathrm{TM}}$ (Thermo Scientific, Waltham, MA, USA) spectrophotometer. Reverse transcriptase was used to prepare cDNA, and the samples were assayed using custom-designed primers (Primer Express software, Applied Biosystems/Life Technologies) and TaqMan ${ }^{\circledR}$ probes used for target genes porcine procollagen type I, II, MMP-1, aggrecan, and reference genes, porcine GAPDH-2, 18S (Table 1), and an ABI PRISM 7900 (Applied Biosystems) for amplification. A comparative CT method was used to quantitate the target genes. A Delta $\mathrm{CT}(\Delta \mathrm{CT})$ for each sample was determined by subtracting the average $\mathrm{CT}$ of the housekeeping gene from the average CT of the target gene. Plotting the data as $2^{-(\triangle \mathrm{CT})}$ normalises the expression relative to the level of a housekeeping gene (Livak and Schmittgen, 2001). This is an exponential value since each CT results in a doubling of the PCR product. Primary cultures that were not stretched but cultured equivalently served as a reference (control group) for the comparison of mRNA levels for the stretched cells (experimental group).

\section{Measurement of [ $\left.{ }^{35} \mathrm{~S}\right]$-sulphate incorporation into GAGs}

To measure newly synthesised glycosaminoglycans (GAG), $20 \mu \mathrm{Ci}$ of $\left[{ }^{35} \mathrm{~S}\right]$ sodium sulphate (NEN Life Science Products, Boston, MA, USA) in $2 \mathrm{~mL}$ of serum-free F-12K medium per culture plate was incubated for $24 \mathrm{~h}$ following CTS. Each culture was then digested with $1 \mathrm{~mL}$ of $125 \mu \mathrm{g} /$ $\mathrm{mL}$ papain (Sigma-Aldrich) in $5 \mathrm{mM}$ cysteine- $\mathrm{HCl}, 0.05 \mathrm{M}$ EDTA and $0.1 \mathrm{M}$ sodium phosphate for $16 \mathrm{~h}$ at $68^{\circ} \mathrm{C}(\mathrm{Kim}$ et al., 1994). The cell supernatants and cell layers were pooled and dialysed against $\mathrm{H}_{2} \mathrm{O}$ until the background was neutral. One $\mathrm{mL}$ of $0.5 \%$ hyaluronic acid in $0.05 \mathrm{M}$ Tris$\mathrm{HCl} \mathrm{pH} 7.5$ was added to $100 \mu \mathrm{L}$ aliquots of the dialysed samples and vortexed. Then $250 \mu \mathrm{L}$ of $2 \%$ cetyltrimethyl ammonium-bromide (CTAB) in $\mathrm{H}_{2} \mathrm{O}$ was added, vortexed, and centrifuged at $1000 \mathrm{~g}$ for $10 \mathrm{~min}$ at room temperature. The pellet was washed twice with $250 \mu \mathrm{L} 0.5 \%$ CTAB in $0.05 \mathrm{M}$ sodium chloride, then resuspended in $1 \mathrm{~mL}$ of methanol and counted in $10 \mathrm{~mL}$ of liquid scintillation fluid.

\section{Colorimetric assay to determine the GAG content (DMB)}

The GAG content in digests of cell cultures was determined using the 1,9-dimethylmethylene blue (DMB) method described by Farndale et al. (1986). Briefly, sample solutions $(50 \mu \mathrm{L})$ were gently mixed with a $200 \mu \mathrm{L}$ of DMB solution in a 96-well microtiter plate and the absorbance at $525 \mathrm{~nm}$ was measured immediately using a Titertec Multiskan Spectrophotometer (Lab Systems, Helsinki, Finland). Absorbance values were quantified against a standard curve of shark chondroitin sulphate C (SigmaAldrich), ranging from $2 \mu \mathrm{g} / \mathrm{mL}$ to $2 \mathrm{mg} / \mathrm{mL}$.

\section{Statistics}

All experiments were performed independently at least three times. Student's $t$-tests, paired $t$-tests, and analyses of variance were used to determine statistical significance.

\section{Results}

\section{Baseline production of collagen and collagenase}

Type I collagen is the predominant protein in annular cells and the major component in the annulus that resists the hoop stress resulting from the hydrostatic compression of the nucleus. Surprisingly, we found no significant differences between primary cultures of annular fibrochondrocytes from older animals compared to those from mature animals for the level of expression of collagen type I as measured by RT-PCR. In contrast, the levels of mRNA for type II collagen and aggrecan were significantly decreased in the older annular cells (Fig. 1). Levels of mRNA for MMP-1 from primary cell cultures showed a small, but significant increase in expression of this enzyme in the fibrochondrocyte cultures from the IVDs of older 
Fig. 1. Comparison of gene expression in porcine annulus fibrosis cells of two different age groups. Primary cultures of cells from mature $(n=7$, $36-54 \mathrm{~kg}, 7-8$ months old) or older ( $n=5,113-136 \mathrm{~kg}, 2.5-3$ years old) pigs were extracted for mRNA and specific genes were quantitated by real time RT-PCR. The mRNA levels are normalised to values for housekeeping genes and plotted as 2-(DCT). Data are presented as mean $\pm \mathrm{SD}(*$ Indicates $p<0.05$ relative to mature tissue).

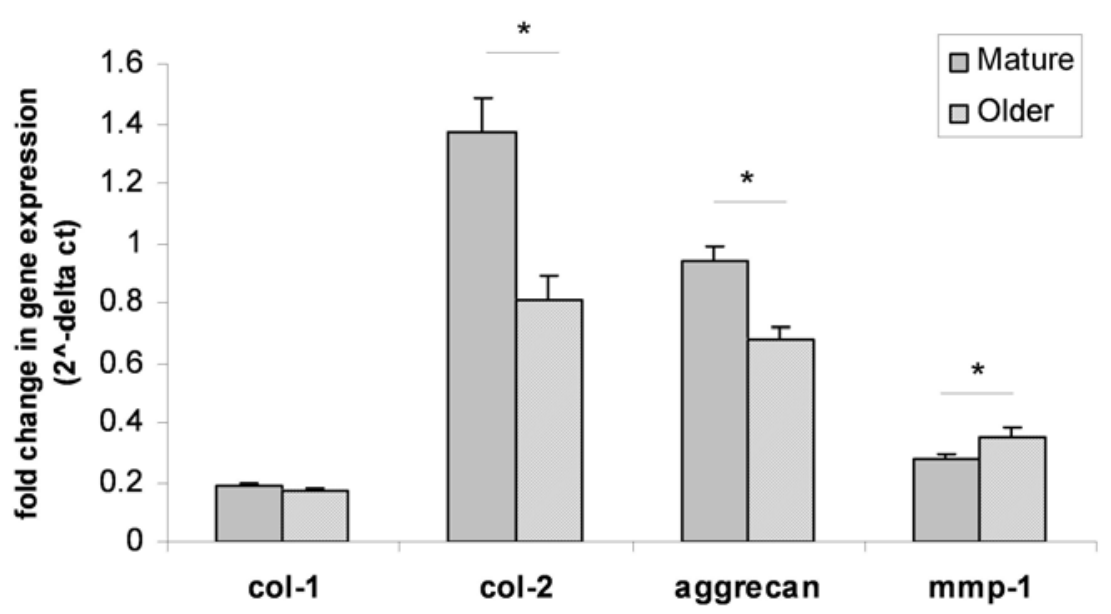

(A)

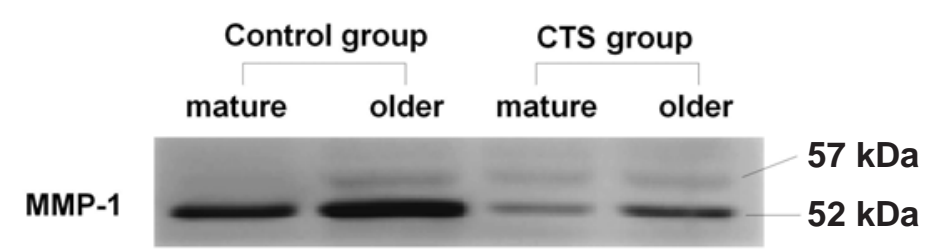

(B)

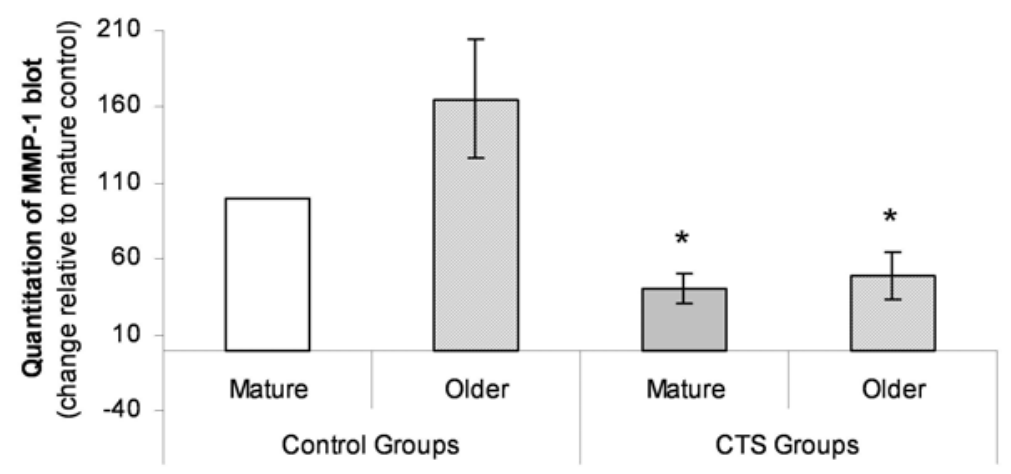

Fig. 2. Downregulation of MMP-1 expression in annulus fibrosus cells by CTS. (A) Western blot analysis of MMP-1 protein in culture supernatants from annulus fibrosus cells of mature and older age groups before and after exposure to CTS. Protein secreted into the culture supernatants during the stretch interval was precipitated and analysed by Western blots using antibodies to porcine MMP-1. (B) Quantitation of unglycosylated form $(52 \mathrm{kDa})$ of immunoreactive bands in culture supernatants from these cells exposed to CTS application or cultured similarly but remaining stationary. Data presented as mean $\pm \mathrm{SD}(*$ Indicates $p<0.05$ relative to each control group; $n=5$ /each age group).

animals (Fig. 1). Increased MMP-1 synthesis by the older cells was confirmed by Western blot analyses of MMP-1 in $24 \mathrm{~h}$ culture supernatants (Fig. 2A), which showed a fourfold difference in MMP-1 protein comparing mature and older cells from control group, respectively. Interestingly, the levels of MMP-1 protein in culture supernatants from annular cells of both ages were significantly decreased with mechanical stimulation (Fig. 2B). These results demonstrate that $0.5 \mathrm{~Hz}$ frequency with a maximum of $10 \%$ of CTS depress MMP-1 expression, with a modest decrease in the protein in the supernatant (Fig. 2).

\section{Collagen and collagenase expression after CTS stimulation}

Fibrochondrocytes from annular tissues of mature pigs when stimulated by CTS showed significant increases in the levels of type II collagen and aggrecan mRNA to 1.5 times of that seen in unstretched controls of the same age (Fig. 3). Annular cells from older animals showed a much larger relative increase of type II collagen and aggrecan expression after CTS as compared to cells from the mature animals. In this animal group, type II collagen mRNA levels had a mean increase of 3.7 fold over the unstretched 


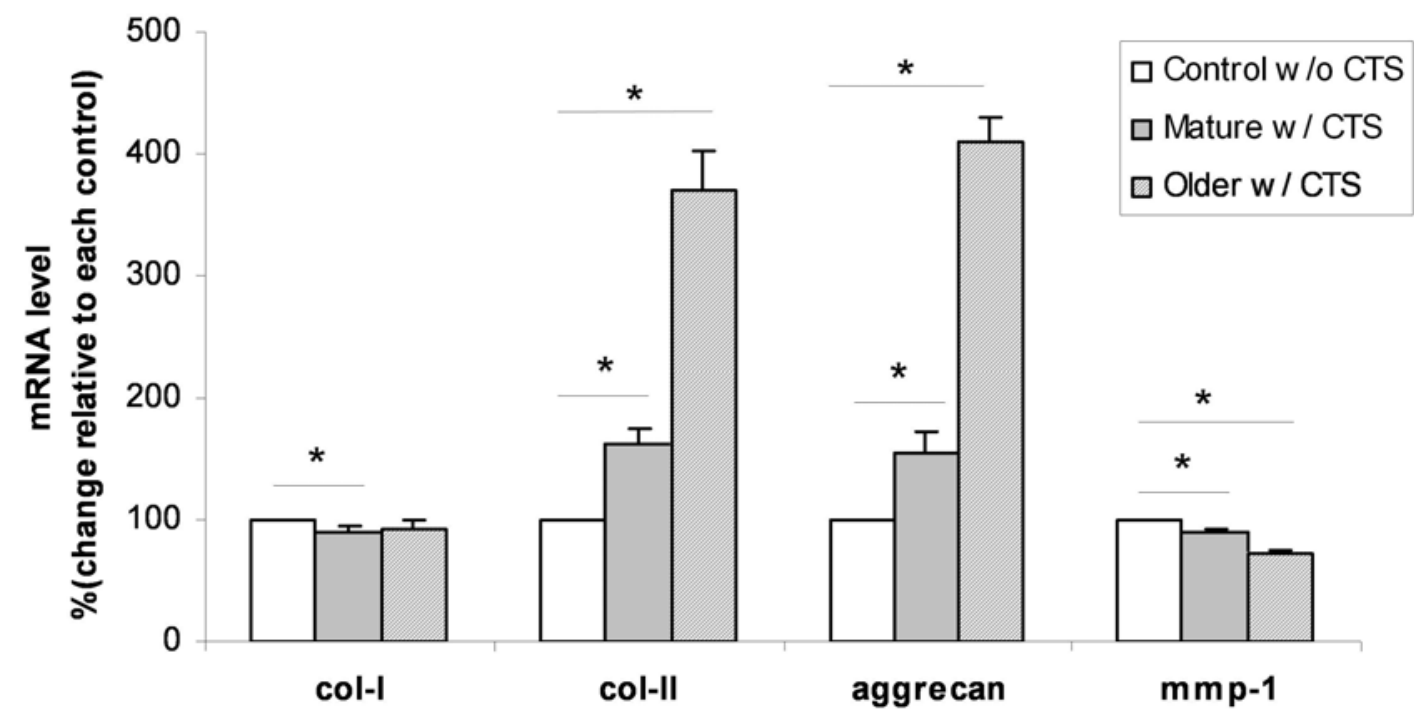

Fig. 3. Change in levels of mRNA for collagen type I, collagen type II, aggrecan and MMP-1 before and after exposure to CTS. Relative gene expression is compared to control cells of the same age that are not stretched. For each gene the expression of the controls is arbitrarily set at $100 \%$. Data presented as mean $\pm \mathrm{SD}$ ( $*$ Indicates $p<0.05$ relative to each control group; $n=5 /$ each age group).

(A)

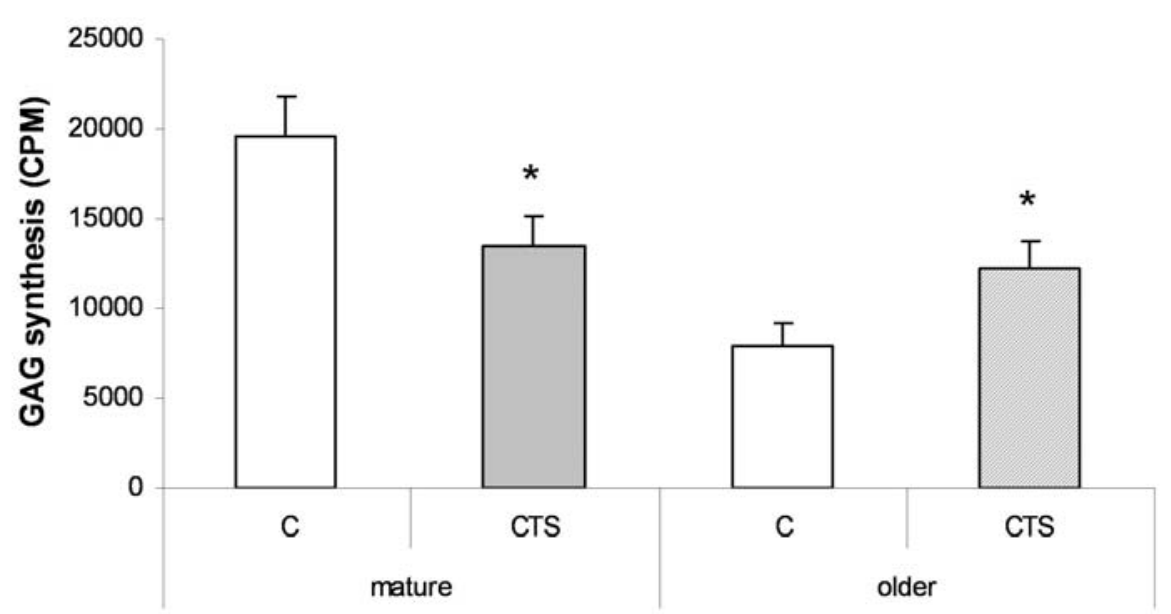

(B)

\begin{tabular}{c|c|c}
\hline \multirow{2}{*}{} & \multicolumn{2}{|c}{ Cell Count $\left(X 10^{5}\right)$ per well } \\
\cline { 2 - 3 } & Before CTS & After CTS \\
\hline \multirow{2}{*}{ Mature } & $($ Mean \pm SD $)$ & $($ Mean \pm SD $)$ \\
Older & $3.49 \pm 0.12$ & $3.51 \pm 0.10$ \\
\hline
\end{tabular}

Fig. 4. Effect of age and mechanical stress on glycosaminoglycan synthesis. (A) Synthesis of glycosaminoglycans in porcine annular cells of two different ages. Primary cultures were cyclically stretched for $24 \mathrm{~h}$ before radiolabelling for $24 \mathrm{~h}$ with $(35 \mathrm{~S})$ sulphate. Culture supernatants and cells were proteolytically digested, pooled, dialysed and the newly synthesised $(35 \mathrm{~S})$ sulphatelabelled glycosaminoglycans were analysed by CTAB precipitation and scintillation counting. (B) Cell numbers unaffected by CTS. The average cell count and standard deviation from two different age groups and two independent experiments before and after CTS. The cell number of both experimental groups did not show any significant change following CTS treatment. Data presented as mean $\pm \mathrm{SD}(*$ Indicates $p<0.05$ relative to control group $(\mathrm{C}) ; n=5$ /each age group). 


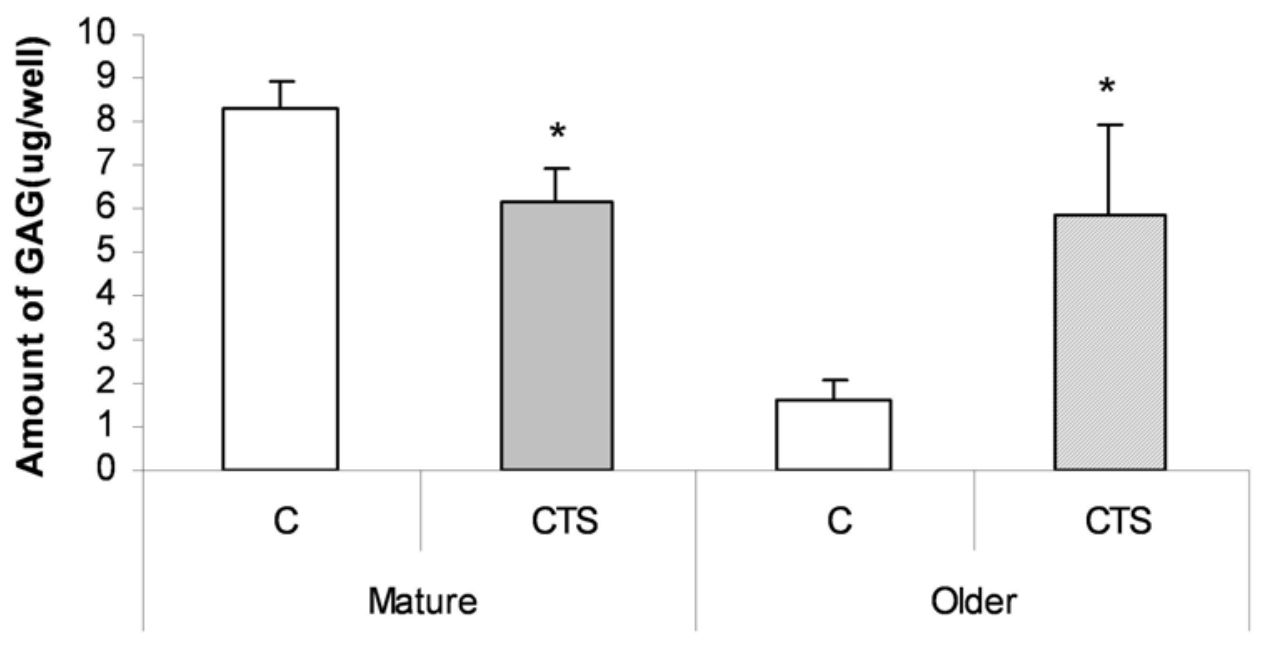

Fig. 5. Total GAG production in different age groups before and after CTS. A 1,9-dimethylmethylene blue (DMB) assay was used to assess sulphated glycosaminoglycan (S-GAG) production. Absorbance values were calibrated against a standard curve of shark chondroitin sulphate C (Sigma-Aldrich). Data presented as mean $\pm \mathrm{SD}$ (* Indicates $p<0.05$ relative to control group (C) of the same age; $n=5$ /each age group).

controls, while the levels of aggrecan increased by 4.1 fold. In contrast, a small but significant decrease was seen in levels of expression of MMP-1 gene in both animal categories after CTS. Mechanical stimulation led to a slight decrease in type I collagen mRNA levels in mature pigs but this gene expression remained unchanged for the older cells (Fig. 3). It should be noted that gene expressions for each group are normalised to their respective unstretched controls that are set to 100 .

\section{Effects of CTS on glycosaminoglycan synthesis}

Proteoglycans are synthesised by AF cells and are relatively enriched in the inner layers of the annular tissue compared to the outer layers (Maeda and Kokubun, 2000). Radioactive labelling with ${ }^{35} \mathrm{~S}$ showed lower incorporation into glycosaminoglycans (GAG) in cell cultures from the older animals compared to those taken from the mature animals (Fig. 4A). The cellular response to CTS stimulation with respect to GAG synthesis differed between the two ages. Application of CTS resulted in a decrease of GAG synthesis in the mature annular cells, while older cells showed an increase of GAG synthesis. The cell numbers of the confluent monolayers treated with CTS did not change (Fig. 4B). The total amount of GAG, as measured colorimetrically, present in the cultures of the unstretched older annular cells was lower than that was present in mature cells paralleling results for incorporation of radioactive sulphate (Fig. 5). Application of CTS caused a slight decrease in the total amount of GAG in the mature annular cells, but an increase of that seen in the older annular cells. These results are similar to those in Fig. 4, which shows a large increase in newly synthesised GAG with CTS in the older cells.

\section{Discussion}

The IVDs contribute to flexibility, load support, and energy dissipation in the spine. In healthy discs, the rates of synthesis and breakdown of the ECM are in equilibrium because of the intricate regulation by growth factors and cytokines (Kawaguchi et al., 1999; Roughley et al., 2002). Disc degeneration has been suggested to be associated with a loss of tissue cellularity through apoptotic-related processes that lead to a diminished generation, organisation, and repair of the ECM (Gruber and Hanley 1998; Lotz et al., 1998; Annunen et al., 1999). Homeostasis of the ECM in the intervertebral discs also has been shown to be regulated by mechanical loading (Handa et al., 1997; Hutton et al., 1999). These findings have been interpreted as indicative of the pivotal role of mechanical stress in ECM degradation and induction of cell apoptosis in the IVD, which combine to produce disc degeneration (Rannou et al., 2004). This interpretation is somewhat discouraging for the exploration of interventional therapies with the exception of cell-based therapy. Our results, however, offer a much more optimistic prognosis for exercise based therapy.

In this investigation, the expression pattern of genes relevant to ECM of the IVDs varied with age. In older cells, expression of collagen type II and aggrecan decreased while that of MMP-1 increased. These expression patterns may reflect metabolic processes in the annulus that vary with age or modulate due to changes in the cellular environment such as the hydration status of the adjacent nucleus or the cross-linking of collagen fibrils (Acaroglu et al., 1995; Horner et al., 2002). The annulus is a heterogeneous tissue with respect to the organisation 
of its ECM. It is highly hydrated, with organised collagen fibres that form a concentric lamellar structure. The type I/type II collagen composition changes gradually moving in from the outer layers, with an enrichment of type II and proteoglycan in the inner layers (Eyre and Muir, 1976; Maeda and Kokubun, 2000). Type II collagen staining has been shown to be reduced in the inner annulus in adult and elderly humans (Nerlich et al., 1997).

The porcine spine as a model for the human spine has been studied in several biomechanical contexts. Although pigs are quadrupeds, as are most mammalian models of spinal biomechanics, they nonetheless exhibit pressures in the same range as experienced by IVDs in humans and have similar facet orientation and ligamentous structures (Yingling et al., 1999; Wenger et al., 2000). The compressive strength of their vertebrae is also in the range reported for humans, suggesting that the complexity of stresses experienced in the daily life of pigs is similar to that of bipeds to the extent that such stresses dictate tissue morphology (Almekinders et al., 1993; Sasaki et al., 2001).

The Flexcell has been used for many years with different CTS protocols for several cell types. Previously published studies have used different frequencies, intensities, or CTS time exposures than those in the present work (Banes et al., 1985; Almekinders et al., 1993). $1 \mathrm{~Hz}$ is the highest frequency that can be used with the Flexcell, and it corresponds to the walking frequency (Winter, 1983; Rannou et al., 2000). Various studies have reported strains between $5 \%$ and $13 \%$, with $20 \%$ being the maximal failure strain evaluated in annular collagen type I fibres. 5 $\%$ strain corresponds to average strain observed in annular collagen fibres from IVDs submitted to compressive stress. Any stretch condition above $12 \%$ change the volume and temperature of culture medium significantly (Brinckmann et al., 1983; Rannou et al., 2000; Rannou et al., 2004; Costi et al., 2007). Gilbert et al. (2010) suggest that AF cells respond differently to changes in time period of applied stress. Expression of matrix degrading enzyme changes within $1 \mathrm{~h}$ of stress whereas expression of matrix proteins only after $24 \mathrm{~h}$. Our rationale for choosing $24 \mathrm{~h}$ exposure for these experiments was also determined by the fact that we did not want cells to undergo stretching in the absence of serum components for more than this time frame. Also, 24 $\mathrm{h}$ is a reasonable period for soluble mediators to accumulate and/or stimulate the cells and in addition, this was the time duration where we saw a reproducible effect. Finally, other investigators have used this interval for studies allowing comparisons with our data (Rannou et al., 2000; Rannou et al., 2004).

Mechanical stimulation using the Flexcell apparatus led to a small change in the expression of collagen type I in the AF of mature discs with no significant change in the cells from older discs. Minimal or no response for expression of type collagen I with mechanical stimulation was similar to results with human and bovine annular cells previously shown (Cs-Szabo et al., 2000; Wuertz et al., 2007). In the present study, the expression of collagen type II and aggrecan increased with mechanical stimulation, while at the same time the expression of MMP-1 was reduced in the annular cells from both mature and older discs. Surprisingly, the magnitude of the response over the unstretched control baseline was significantly greater in the older cells. As the older cells are clearly mechanoresponsive to CTS, we postulate that the basal expression of decreased type II collagen and aggrecan and increased MMP-1 relative to the mature cells reflect reduced mechanical stress experienced in vivo as compared to that experienced by the mature pigs.

Variations in the mechanical stresses in the annulus due to aging could result from increased cross-linking of IVD collagens (Banes et al., 1990; Skaggs, 1994), variation in the hoop stress resulting from changes in the nucleus composition, or simply decreased physical activity of the older animals (Lotz et al., 2002; Rannou et al., 2004). Various independent studies have been conducted to try to explain the various effects aging can have on the IVD (Silberberg et al., 1979; Iatridis et al., 1999). Kurutz (2006) reported that in vivo tensile deformability of human lumbar-lumbosacral motion segments and discs was decreased in older individuals while Pokharna and Phillips (1998) showed that an increase in pentosidine crosslinks in the disc occurs with age. Adams et al. (2000) using a pressure transducer to spatially determine stress profiles of discs under constant compression, showed that age-related degenerative changes reduced the sagittal diameter of the functional nucleus by approximately $50 \%$ and that the pressure within it falls by $30 \%$. This impacts the stress experienced by the encapsulating annular tissues. In this study, we utilised the information from these studies to explain how composition of ECM changes with age and how controlled mechanical stimulation can modulate the ECM genes. The intensity, frequency, and vacuum signalshape of CTS used in our experiments were not varied and therefore the mechanical stress was not maximised. Further studies are needed to investigate the optimal type and characteristic of mechanical stress, not only on the annular cells (AF), but on the nuclear cells (NP) as well.

Our original hypothesis that mechanical stress could modulate the degenerative processes observed in the annular cells from older IVDs was based on studies showing that many MMP genes show reduced expression following dynamic tensile strain (Xu et al., 2000; Deschner et al., 2006). Indeed, this was the case for both mature and older annular cells in the present study. More relevant to health considerations is the fact that mechanical stress produced increased proteoglycan synthesis and type II collagen expression along with the reduced levels of collagenase in cells of the AF from older animals. Clinically, enhancement of the anabolic side of AF metabolism by exercise therapy causing spinal stretching by flexion, extension, rotation, and lateral bending could prevent or reduce annular degeneration. Animal studies have demonstrated that motion and exercise increase disc metabolism (Holm and Nachemson, 1983; Kroeber et al., 2002). The current experiments confirm these findings and show mechanistic data supporting the benefits of exercise therapy and increased physical activity for the older spine. 


\section{Acknowledgements}

This material is based upon work supported VA Merit Review award to Dr. Hasty by Office of Research and Development, Department of Veterans Affairs and funds from the UTHSC Center of Excellence in Connective Tissue Diseases.

\section{References}

Acaroglu E., Iatridis J, Setton L., Foster R., Mow V, Weidenbaum M (1995) Degeneration and aging affect the tensile behavior of human lumbar annulus fibrosus. Spine 20: 2690-2701.

Adams MA, Freeman BJC, Morrison HP, Nelson IW, Dolan P (2000) Mechanical initiation of intervertebral disc degeneration. Spine 25: 1625-1636.

Almekinders LC, Banes AJ, Ballenger CA (1993) Effects of repetitive motion on human fibroblasts. Med Sci Sports Exerc 25: 603-607.

An HS, Anderson PA, Haughton VM, Iatridis JC, Kang JD, Lots JC, Natarajan RN, Oegema TR, Roughley P, Setton LA, Urban JP, Videman T, Andersson GBJ, Weinstein JN (2004) Disc degeneration: Summary. Spine 29: $2677-2678$.

Annunen S, Paassilta P, Lohiniva J, Perala M, Pihlajamaa T, Karppinen J, Tervonen O, Kroger H, Lahde S, Vanharanta H, Ryhanen L, Goring HH, Ott J, Prockop DJ, Ala-Kokko (1999) An allele of COL9A2 associated with intervertebral disc disease. Science 285: 409-412.

Baer AE, Wang JY, Kraus VB, Setton LA (2001) Collagen gene expression and mechanical properties of intervertebral disc cell-alginate cultures. J Orthopaed Res 19: $2-10$.

Banes AJ, Gilbert J, Tylor D, Monbureau O (1985) A new vacuum-operated stress providing instrument that applies static or variable duration cyclic tension or compression to cells in vitro. J Cell Sci 75: 35-42.

Banes AJ, Link GW, Gilbert JA, Tran STR, Monbureau O (1990) Culturing cells in a mechanically active environment. Am Biotechnol Lab 8: 12-22.

Barrick WT, Schofferman JA, Reynolds JB, Goldthwaite ND, McKeehen M, KeaWhite AH (2000) Anterior lumbar fusion improves discogenic pain at levels of prior posterolateral fusion. Spine 25: 853-857.

Brinckmann P., Frobin W., Hierholzer E, Horst M (1983) Deformation of the vertebral end-plate under axial loading of the spine. Spine 8: 851-856.

Costi JJ, Stokes IA, Gardner-Morse M, Laible JP, Scoffone HM, Iatridis JC (2007) Direct measurement of intervertebral disc maximum shear strain in six degrees of freedom: Motions that place disc tissue at risk of injury. J Biomech 40: 2457-2466.

Cs-Szabo G, Juan D, Turumella V, Masuda K, Thonar E, An H (2000) Changes in mRNA and protein levels of proteoglycans of the annulus fibrosus and nucleus pulposus during intervertebral disc degeneration. Spine 27: 2212 2219.

Deschner J, Rath-Deschner B, Agarwal S (2006) Regulation of matrix metalloproteinase expression by dynamic tensile strain in rat fibrochondrocytes Osteoarthritis Cartilage 14: 264-272.

Ekstrom L, Holm S, Holm AK, Hansson T (2004) In vivo porcine intradiscal pressure as a function of external loading. J Spinal Disord Tech 17: 312-316.

Eyre DR, Muir H (1976) Types I and II collagens in intervertebral disc. Interchanging radial distributions in annulus fibrosus. Biochem J 157: 267-270.

Farndale RW, Buttle DJ, Barrett AJ (1986) Improved quantification and discrimination of sulfated glycosaminoglycans by use of dimethylene blue. Biochem Biophys Acta 883: 173-177.

Ganey T, Libera J, Moos V, Alasevic O, Fritsch K, Meisel H, Hutton W (2003) Disc chondrocyte transplantation in a canine model: A treatment for generated or damaged intervertebral disc. Spine 28: 2609-2620.

Gilbert HT, Hoyland JA., Millward-Sadler SJ (2010) The response of human annulus Fibrosus cells to cyclic tensile strain is frequency-dependent and altered with disc degeneration. Arthritis Rheum 62: 3385-3394.

Gillett NA, Gerlach R, Cassidy JJ, Brown SA (1988) Age-related changes in the beagle spine. Acta Orthop Scand 59: 503-507.

Gruber HE, Hanley EN (1998) Analysis of aging and degeneration of the human intervertebral disc. Spine 23: 751-757.

Handa T, Ishihara H, Ohshima H, Osada R, Tsuji H, Obata K (1997) Effects of hydrostatic pressure on matrix synthesis and matrix metalloproteinase production in the human lumbar intervertebral disc. Spine 22: 1085-1091.

Holm S, Nachemson A (1983) Variations in the nutrition of the canine intervertebral disc induced by motion. Spine 8: $866-874$.

Hoogendoorn WE, van Poppel MNM, Bongers PM, Koes BW, Bouter LM (2000) Systematic review of psychosocial factors at work and private life as risk factors for back pain. Spine 25: 2114-2125.

Horner HA, Roberts S, Bielby RC, Menage J, Evans H, Urban JPG (2002) Cells from different regions of the intervertebral disc: Effect of culture system on matrix expression and cell phenotype. Spine 27: 1018-1028.

Hutton WC, Elmer WA, Boden SD, Hyon S, Toribatake Y, Tomita K, Hair GA (1999) The effect of hydrostatic pressure on intervertebral disc metabolism. Spine 24: 1507-1515.

Iatridis JC, Mente PL, Stokes IAF, Aronsson DD, Alini M (1999) Compression-induced changes in intervertebral disc properties in a rat tail model. Spine 24: 996-1002.

Kawaguchi Y, Osada R, Kanamori M, Ishihara H, Ohmori K, Matsui H, Kimura T (1999) Association between an aggrecan gene polymorphism and lumbar disc degeneration. Spine 24: 2456-2460.

Kelsy JL, Mundt DJ, Golden AL (1992) Epidemiology of low back pain. In: Jayson MIV (ed) The Lumbar Spine and Back Pain, 4th ed. Churchill Livingstone, Edinburgh, pp 537-550.

Kim YJ, Sah RL, Grodzinsky AJ, Plaas AH, Sandy JD (1994) Mechanical regulation of cartilage biosynthetic behavior: physical stimuli. Arch Biochem Biophys 311: $1-12$. 
Klein-Nuland J, Veldhuijzen JP, Burger EH (1986) Increased calcification of growth plate cartilage as a result of compressive force in vitro. Arthritis Rheum 29: $1002-$ 1009.

Kroeber MW, Unglaub F, Wang H, Schmid C, Thomsen M, Nerlich A, Richter W (2002) New in vivo animal model to create intervertebral disc degeneration and to investigate the effects of therapeutic strategies to stimulate disc regeneration. Spine 27: 2684-2690.

Kurutz M (2006) Age-sensitivity of time-related in vivo deformability of human lumbar motion segments and discs in pure centric tension. J Biomech 39: 147-157.

Lam KS, Carlin D, Mulholland RC (2000) Lumbar disc high-intensity zone: the value and significance of provocative discography in the determination of the discogenic pain source. Eur Spine J 9: 36-41.

Livak KJ, Schmittgen TD (2001) Analysis of relative gene expression data using real-time PCR and the 2- $\Delta \Delta \mathrm{CT}$ method. Method 25: 402-408.

Lotz JC, Colliou OK, Chin JR, Duncan NA, Liebenberg E (1998) Compression-induced degeneration of the intervertebral disc: an in vivo mouse model and finiteelement study. Spine 23: 2493-2506.

Lotz JC, Hsieh AH, Walsh AL, Palmer EI, Chin JR (2002) Mechanobiology of the intervertebral disc. Biochem Society Trans 30: 853-858.

Luoma K, Riihimaki H, Luukkonen R, Raininko R, Viikari-Juntura E, Lamminen A (2000) Low back pain in relation to lumbar disc degeneration. Spine 25: 487-492.

Maeda S, Kokubun S (2000) Changes with age in proteoglycan synthesis in cells cultured in vitro from the inner and outer rabbit annulus fibrosus. Responses to interleukin-1 and interleukin-1 receptor antagonist protein. Spine 25: 166-169.

Matsumoto T, Kawakami M, Kuribayashi K, Takenaka T, Tamaki T (1999) Cyclic mechanical stretch stress increases the growth rate and collagen synthesis of nucleus pulposus cells. Spine 24: 315-319.

Naylor A, Happey F, Macrae T (1954) The collagenous changes in the intervertebral disc with age and their effects on its elasticity, an X-ray crystallographic study. Br Med J 2: 570-573.

Nerlich AG, Schleicher ED, Boos N (1997) Immunohistologic markers for age-related changes of human lumbar intervertebral discs. Spine 22: 2781-2795.

Pokharna HK, Phillips FM (1998) Collagen crosslinks in human lumbar intervertebral disc aging. Spine 23: 16451648.

Rajpurohit R, Risbud MV, Ducheyne P, Vresilovic EJ, Shapiro IM (2002) Phenotypic characteristics of the nucleus purposes: expression of hypoxia including factor-1, glucose transporter-1 and MMP-2. Cell Tissue Res 308: 401-407.

Rannou F, Poiraudeau S, Foltz V, Boiteux M, Corvol M, Revel M (2000) Monolayer annulus fibrosus cell culture in a mechanically active environment: Local culture condition adaptations and cell phenotype study. J Lab Clin Med 136: 412-421.

Rannou F, Lee TS, Zhou RH, Chin J, Lotz J, Mayoux-B MA, Barbet JP, Chevrot A, Shyy JYJ (2004) The role of the mitochondrial pathway in annulus fibrosus cell apoptosis induced by overload. Am J Pathol 164: 915-924.

Robertson JT (1993) The rape of the spine. Surg Neurol 39: 5-12.

Roughley PJ, Alini M, Antoniou J (2002) The role of proteoglycans in aging, degeneration and repair of the intervertebral disc. Biochem Soc Trans 30: 869-874.

Sasaki M, Takahashi T, Miyahara K, Hirose AT (2001) Effects of chondroitinase $\mathrm{ABC}$ on intradiscal pressure in sheep: An in vivo study. Spine 26: 463-468.

Silberberg R, Aufdermaur M, Adler J (1979) Degeneration of the intervertebral discs and spondylosis in aging sand rats. Spine 103: 231-235.

Sive JI, Baird P, Jeziorsk M, Watkins A, Hoyland JA, Freemont AJ (2002) Expression of chondrocyte markers by cells normal and degenerate intervertebral discs. J Clin Pathol Mol Pathol 55: 91-97.

Skaggs D, Weidenbaum M, Iatridis J, Ratcliffe A, Mow V (1994) Regional variation in tensile properties and biochemical composition of the human lumbar annulus fibrosus. Spine 19: 1310-1319.

Smith L, Hochmuth RM (1982) Effect of wheat germ agglutinin on the viscoelastic properties of erythrocyte membrane. J Cell Biol 94: 7-11.

Wenger KH, Woods JA, Holecek A, Eckstein EC, Robertson JT, Hasty KA (2005) Matrix remodeling expression in annulus cells subjected to increased compressive load. Spine 30: 1122-1126.

Winter DA (1983) Biomechanical motor patterns in normal walking. J Mot Behav 15: 302-330.

Wuertz K, Urban JP, Klasen J, Ignatius A, Wilke HJ, Claes L, Neidlinger-Wilke C (2007) Influence of extracellular osmolarity and mechanical stimulation on gene expression of intervertebral disc cells. J Orthoped Res 25: 1513-1522.

Xu Z, Buckley MJ, Evans CH, Agarwal S (2000) Cyclic tensile strain acts as an antagonist of IL-1 beta actions in chondrocytes. J Immunol 165: 453-460.

Yingling VR, Callaghan JP, McGill SM (1999) The porcine cervical spine as a model of the human lumbar spine: An anatomical, geometric, and functional comparison. J Spinal Disord 12: 415-423.

\section{Discussion with Reviewers}

Reviewer II: One could easily argue that $10 \%$ strain applied for $24 \mathrm{~h}$ represents a supraphysiological loading. Do you expect that a lower magnitude of strain could elicit a similar response or if the response could occur within a shorter time period?

Authors: We believe that a lower magnitude of stretch or a shorter time period can produce biologically significant results. But we hypothesise that results will be different from the ones observed in the present study. Rannou et al. (2004) (text reference) observed that at $1 \%$ stretch magnitude, the amount of proteoglycan secreted in the culture media, is not significantly different from the unstretched controls. But higher stretch levels of $5 \%$ result in a decrease in the amount of proteoglycan. Also, 
Gilbert et al. (2010) (text reference) suggest that AF cells respond differently to changes in time period of applied stress. Matrix degrading enzyme gene expression changes within $1 \mathrm{~h}$ of stress whereas the matrix protein gene expression changes only after $24 \mathrm{~h}$. Our rationale for choosing $24 \mathrm{~h}$ exposure for these experiments was also determined by the fact that we did not want cells to undergo stretching in the absence of serum components for more than this time frame. Also, $24 \mathrm{~h}$ is a reasonable period for soluble mediators to accumulate and/or stimulate the cells. Moreover, this was the time duration where we saw a reproducible effect.

Reviewer III: What is the scientific argument just to look at a $24 \mathrm{~h}$ time window after stretching? Also for therapeutic purposes the $24 \mathrm{~h}$ time frame is not very clear.

Authors: The main purpose of our study is to investigate how cells from different age groups respond to mechanical stimulation using cyclic tensile stress (CTS). It has been previously shown that $24 \mathrm{~h}$ of continuous stretching has a significant effect on the extracellular matrix composition as is shown by others (Rannou et al., 2004; Gilbert et al., 2010) (text references), allowing comparisons with our data and providing a format for testing the effect of age on this response. This time interval produced significant changes and offers several advantages. Other justifications for choosing this time period were to allow the use of serum free medium, to minimise effects of serum growth factors that might mask age related differences. We also wanted to allow sufficient time for soluble molecules or mediators to accumulate and/or stimulate the cells. The data suggests that the cells from older aged animals react positively to mechanical stress, which posits that mechanical stimulation may be therapeutic for stimulating extracellular matrix production and accumulation in IVD cells from older individuals although the time frame and duration of this mechanical stimulation has yet to be determined. We believe that shorter, more frequent intervals would be effective in vivo. However, permanent changes in micro-molecular composition of the IVD will depend on various factors - age, physical lifestyle, genetic disposition, frequency of stimulation, and time duration of therapy. A significant number of studies have to be performed to justify this theory.

Reviewer III: The up-regulation of aggrecan and collagen type 2 after $24 \mathrm{~h}$ is quite remarkable (Fig. 3). However, will the gene expression be long-lasting or would it go back to normal level immediately after stopping the CTS? Authors: As we do not know the pathway by which CTS stimulates aggrecan or type 2 collagen expression, it is difficult to predict. Theoretically, as more extracellular matrix is formed, it could function to insulate the cell from the mechanical stretching. Alternatively, if matrix accumulation is due to a secreted growth factor or mediator then the expression might be prolonged. It is our intention to expand these studies.

Reviewer III: It is amazing that MMP1 is responding so quickly to CTS loading. Do you think that after stimulation the expression is increased again to the original level?

Authors: Our previous studies studying a time course of the response of normal articular chondrocytes to CTS showed that the MMP-1 response was a relatively late expression which was not seen until $24 \mathrm{~h}$ (Huang et al., 2007; additional reference), while collagen and aggrecan expression were seen at much earlier times. Asking if the expression is increased to the original level is an intriguing question that would offer an alternate interpretation of the data.

\section{Additional Reference}

Huang J, Ballou LR, Hasty KA (2007) Cyclic equibiaxial tensile strain induces both anabolic and catabolic responses in articular chondrocytes. Gene 404: 101-109. 